\title{
Pursuing Integral Harmony in Sustainable Human Evolution
}

\author{
Kensei Hiwaki $^{1^{*}}$, Frank Hassard ${ }^{2}$ \\ ${ }^{I}$ Tokyo International University (TIU, Japan) and the International Institute for Advanced Studies in Systems \\ Research and Cybernetics (IIAS, Canada) \\ ${ }^{2}$ The International Institute for Advanced Studies in System Research and Cybernetics (IIAS, Canada) \\ *Corresponding Author: Kensei Hiwaki, Tokyo International University (TIU, Japan) and the \\ International Institute for Advanced Studies in Systems Research and Cybernetics (IIAS, Canada)
}

\begin{abstract}
This article presents a hypothesis of future human evolution that is assisted by our normative framework of social value system based on "imaged" sound society-specific holistic culture ("Native Culture") in each society-the normative framework of Integral Harmony. In view of a wide range of evolutionary literature introduced after Charles Darwin's monumental book in1859, it has become clear that human evolution is not totally biological. Also, it has become evident that human evolution is positively influenced by the complex spiritual-and-intellectual human factor. In other words, such human factor has created diverse Native Cultures which, in turn, influenced human evolution. (Darwin himself touched upon cultures in his second work in 1871.) In view of future human evolution, this article argues that the pervasive influence of the core values underpinning Modern Civilization have undermined the world's Cultural diversity and set humanity on an unsustainable evolutionary trajectory. In order to help make a turnabout of such evolution, this article devises a more comprehensive theoretical model which combines Richard Dawkins' concept of "Meme" with "Gene" and our term "Civie" denoting the complex human-and-Cultural factor. We propose their trilateral interaction which could provide a framework for sustainable human evolution if accompanied by the framework of Integral Harmony.
\end{abstract}

Keywords: Human evolution, communicative phenomenological process, epigenetics, Civie-Meme-Gene interaction, integral harmony, native culture, viable human future,

\section{INTRODUCTION}

Presently, more than seven billion people live on the relatively unchanged land surface of our Insular Planet-Earth. Within a brief period of just three centuries it has been well demonstrated that the course of human evolution has been threatened by the harmful effects of a progressive Modern Civilization which was originated in the Western hemisphere. Through the agency of economic globalization it has exploited natural resources to a dangerous point of depletion, while at the same time accelerating a worldwide movement towards standardization, subjugation, unification and mechanization, culminating in a world of increasingly isolated "atomized" human beings.

As a result, more and more are compelled to engage in a form of "life-or-death" competition to satisfy human greed, damaging the natural environment with human ignorance and limited capacity. This is met by a rapid growth of production, extremely lopsided distribution, the seemingly endless changes in working methods-and-conditions, industrial relations for the excess of market-centered goods-andservices as well as for the idolization of celebrity figures and the fashions and objects and other material aspirations much beyond human needs justify.

The harm this has wrought on society-specific holistic cultures ("Native Cultures") across the world is palpable and (we believe) is the root cause of a marked decline of vital human-personal qualities including personal morality, social ethics, sound social value and belief systems (among other things) which has brought our human and ecological systems to a point of near collapse. Such a predicament (we suggest) warrants a complete re-evaluation of what we actually mean by "Human Evolution".

Most well-established ideas about evolution were based on the modern scientific "mechanical" view of the Universe popularized by the European Enlightenment - an intellectual movement which 
dominated the world of ideas in Europe during the $18^{\text {th }}$ Century. "Mechanical" in this sense refers to the belief that natural wholes (principally living things, including people, society and culture) are like machines or artifacts composed of parts lacking any intrinsic relationship to each other, and with their order imposed from without. Mechanization forms the basis of Rene Descartes philosophy and the modern scientific method which stemmed from this, which, in its institutional-socialized form, is known as Cartesianism.

It has been suggested that these well-established ideas were born from a motivation to explicate the "creative hand" of God in Christian faith [1]. Crucially, however, the concept of Biological Evolution after the mid- $18^{\text {th }}$ Century became increasingly associated with the progress of human society-a view which first emerged in France and soon after in England where it was promoted by such figures as Herbert Spencer, Charles Darwin, and Alfred Wallace (among others) in the $19^{\text {th }}$ Century.

However, though variously argued by many natural and social scientists down the ages, the question of human evolution has by no means been settled conclusively. We contend that this is mainly due to insufficient knowledge and comprehension of human complexity which cannot be fully explicated by means of the mechanistic methods common to "Cartesian" science.

A recent example of an alternative approach to evolution has been offered by the well-known evolutionary biologist, Richard Dawkins, which warrants further attention. In his book, The Selfish Gene [2], Dawkins proposed the concept of "Meme" - defined as a self-reproducing pseudo-genetic code which he considered to be an important factor in human evolution. Dawkins arrived at the term "Meme" after looking for a monosyllabic word similar to "Gene" in pronunciation, as well as a word broadly indicating "human culture" and "imitation". His aim was to interpret Meme in terms of a "unit of culture" and a "unit of imitation" which he conceived in relation to the English meaning of "memory" (which relates to culture and imitation) [2]. Following his detailed discussion of Gene and its ex post interpretation as "selfish", Dawkins characterized Meme in terms of a "cultural" counterpart to the "biological" Gene. From this basis he proposed that any change in human culture was necessarily evolutionary and attributable to Meme.

According to Dawkins then, a broad meaning of human imitation and memory capabilities was represented in terms of a self-reproducing Meme. Hence, Dawkins considered Meme as a living structure to be proliferated by human brains, which he attributed to the human cultural feature that exhibits comparatively rapid changes in evolutionary styles as seen, for example, in clothing, food, rituals, habits, arts, architecture, skills, thoughts, slogans, musical pieces and such like. Thus, Meme considered in relation to the concept of "God" (for example) has found expression and been reinforced by the "Meme" of architecture, rituals, rules, music, arts, and the church (including its dogmatic and literary tradition) and so on.

After describing both Meme and Gene as selfish, Dawkins also offered an insight into "human peculiarity" or the human gift of "deliberate foresights" - a natural anticipatory quality which neither Gene nor Meme in and of itself possesses. However, by introducing "deliberate foresights" and characterizing Gene and Meme as "selfish", we contend that Dawkins invariably smoothed over the many underlying human complexities at play in relation to the so-called "adaptations, mutations and selections of the fittest". In other words, the concept of Meme on its own is insufficient for addressing the complexity of humanness, personhood, intellectual advancement and spiritual development $[3,4]$ - all of which we suggest ultimately informs and directs human evolution. In view of this, we believe it is necessary to incorporate a third factor which is no less fundamental to human evolution; that is, "Civie" - [pronounced "civi"] - to broadly describe the "self-civilizing feature" and/or "civility/civilities of humanity" [5] commonly associated with a well-functioning Native Culture.

Now, the term "Native Culture" as used in this paper refers to a reasonably sound native societyspecific holistic way of life which collectively encompasses the long-accumulated totality of personal and societal experiences including knowledge, skills, wisdom, values, beliefs, insight, foresights, ways and mores, customs, traditions, linguistic and other means of communication (among other things). Conceived as such, "Native Culture" provides the link between the past, the present and the future as well as the meta-contextual foundation for human judgment and action. Importantly, while Dawkins' Meme specifies "unit of culture" and/or "unit of imitation" - and thus essentially refers to 
particularistic-effects - our concept of Civie more broadly refers to complex-holistic factors pertaining specifically to the relevant culture/people/society.

We uphold that a constantly enriched, reasonably sound Native Culture is most important for the generation of a sound social value system which creates, integrates, enriches and sustains these natural human-evolutionary qualities/capacities. Thus, we argue in favor of a resuscitation and enrichment of the diverse Native Cultures across the world as a means of overcoming the ills caused by Modern Civilization, while at the same time providing a means by which humanity might return to a more appropriate and sustainable evolutionary trajectory.

To that end, this paper draws on a wide range of literature and experimental evidence deriving from philosophy, quantum physics, neuroscience, evolutionary psychology and evolutionary biology and epigenetics (among others) to present a more comprehensive understanding of human evolution. Building on this it presents a new theoretical model which combines Dawkins' concept of "Meme" with the biological "Gene" and our own term "Civie", denoting the complex human-Cultural factor. The Civie-Meme-Gene trilateral interaction could provide a framework for sustainable human evolution with the help of the normative framework of "Integral Harmony". The framework of "Integral Harmony" is discussed in detail later and proposed as a means by which humankind might enhance the necessary human qualities to re-direct the course of human evolution in the way desired.

\section{Human Evolution: a Communicative Phenomenological Process}

\subsection{Science and the Question of Objectivity}

The word "evolution" commonly invokes Darwin's theory of "Natural Selection" which proposed that life on earth developed gradually by adapting to its environment. Biologists today, for the most part, agree on this basic assumption despite vast disagreement in respect of how evolution occurs. In this connection, it is noteworthy that the historic dimension represented by Darwin's allusion to "Spiritual Evolution" in his The Descent of Man (1871) [6] has largely been forgotten. Hence now when people refer to evolution they generally tend to think only in terms of "Biological Evolution".

Notwithstanding, it was in this second great work, published some twenty-two years after his Origin of Species (1859) [7], that Darwin asserted that human character traits and mental characteristics are inherited in the same way as physical characteristics, suggesting that Natural Selection was a more complex phenomenon than Darwin or his contemporaries ever understood. In this connection, Darwin further reasoned that, 'belief in all-pervading spiritual agencies seems to be universal; and apparently follows from a considerable advance in man's reason, and from a still greater advance in his faculties of imagination, curiosity and wonder' [6]. From this basis he proposed that "Native Culture" is the basis of Spiritual Evolution, concluding that, "The idea of a universal and beneficent Creator does not seem to arise in the mind of man, until he has been elevated by long-continued culture' [6].

What is more, with the recent development of the so-called "Big Bang Theory" science has more recently become preoccupied with "Physical Evolution"- that is, the evolution of physical matter itself, which cannot be easily explained in terms of Natural Selection or Spiritual Evolution.

Despite these complexities, there appears to be a remarkable consistency in the way in which a fundamentally materialistic viewpoint prevails over any non-materialistic one-which is arguably a result of the long-standing prevalence of the highly specialized mechanical-Cartesian thinking of the scientific and political institutions of the West stemming historically from the Enlightenment.

Indeed, it has been argued that ever since Descartes (1596-1650) the historic role of science has consisted precisely in attempting to make the world objective by methodologically eliminating the influence of the interpreter on understanding - a radical, modern, progressive ideology which became manifested in the systematic pursuit of abstract (detached or faceless) "mechanical" knowledge. Through the process of time this would lead to the formation of a new kind of socialized matrix of highly circumscribed learning which would come to dominate the West and suppress and extinguish anything and everything that could not be defined by its own narrow set of values and techniques.

We contend that mechanization did not permit sufficient space for the values and other humanistic qualities which may have accumulated by "long-continued culture". It was in this context that Darwin 
exclaimed that, 'My mind seems to have become a kind of machine for grinding general laws out of large collections of facts, but why this should have caused the atrophy of that part of the brain alone, on which the higher tastes depend, I cannot conceive...' [6]. Darwin's allusion to the 'atrophy of his brain' is important to this paper in as much as it suggests that he was at least in some sense aware of the human evolutionary consequences of excessive mechanization.

Understanding the fundamental way in which human beings make sense of the world goes to the heart of human existence and must we believe be central to any new conception of human evolution. With this in mind, there are two key points to consider for our present purpose: i. the classical "mechanical" scientific assumption that there actually exists an objective reality which can meaningfully be observed and explained in such a "detached" way, and: ii. that information (or data) is the essential ingredient in contributing to our understanding of that assumed reality-communicating a world in which there is no sense that the scientist (or observer) might actually be a constitutive agent of that reality.

Now, the question as to whether there actually is an objective "physical" reality has preoccupied the minds of philosophers for many generations. Kant, for example, famously contended that the way in which our minds operate on the world is dictated by the way our minds are constituted which, for him, did not derive from experience but was rather applied to experience. In other words, according to Kant, we bring to bear on the world not only our sense experience but also our ideas that pre-exist at the level of consciousness - which Kant referred to as "concepts of the understanding" [8]. Accordingly, for Kant, these ideas were a priori truths; which is to say, they come before any experience and they shape the experiences we subsequently have (i.e. according to their constitution).

If we accept this general premise, then it logically follows that we can have no direct knowledge of the world as it is prior to the moment when this mediation takes place. Kant referred to this "premediated" world as "the thing in itself", or perhaps more accurately, "the thing (or world) as it really is"-as distinct to how it may appear to our senses. The world that appears to our senses "postmediation" he called the phenomenal world [8]. From this basis Kant challenged the idea that the physical world we experience is objective and independent with the notion that what we understand of the world is determined by our mind (i.e. by the ideas we impose upon it).

This way of thinking would come to have great bearing on how science and our subsequent understanding of reality would develop post-Darwin. Einstein's theory of relativity, for example, is widely acknowledged as a logical consequence of Kant's earlier ideas [9]. Crucially, Kant recognized that the human ability to conceptualize reality rather than being simply objective is actually fundamentally programmed to develop without being dependent upon experience and is therefore largely conditioned (genetically?) by evolutionary processes - a view which was given great impetus with the invention of Quantum Physics.

\subsection{Quantum Mechanics and the Communicative Turn}

It had long been established that light behaves like a wave which moves at a constant speed through space. But it was not until 1924 that the concept that matter (particles with mass) also behaves like a wave was proposed by Louis de Broglie (1892-1927) who won the Nobel Prize for Physics in 1929 after the wave-like behavior of matter was first demonstrated by the Davisson-Germer experiment $[10,11]$.

The quantum mechanical principle of "Wave-Particle Duality" duly proposes that light and other subatomic particles (such as electrons) sometimes act like a wave and at other times like a particle. Crucially, it was the uncertainty this created that lead some to the suggestion that it is the very process of observation which affects the (physical) system in such a way as to cause the electron to "change" from being a wave (a natural state which infers perpetuity) to becoming a particle in a uniquely specific location in space and time - an unnatural state which corresponds to what we understand to be physical reality. This phenomenon became known as "Wavefunction Collapse" and was central to the so-called "Measurement Problem" - a problem which has beleaguered the world of physics for much of the last century and has hitherto not been conclusively resolved (For further reading see: [12, $13,14])$. 
Related to this, John von Neumann and (later) Eugene Wigner-both of the 'Kantian' school一came to develop the von Neumann-Wigner interpretation in which human consciousness is postulated as necessary for the completion of the process of quantum measurement $[15,16,17]$. Crucially, the claim that consciousness may be required to collapse the wavefunction brought with it a pronounced anthropomorphic dimension to quantum theory by suggesting that nothing happens in the universe unless some observer becomes conscious of it.

In a similar way Wheeler's more recent "Participatory Anthropic Principle" (PAP) further suggested that, "we are participants in bringing into being not only the near and here, but [also] the far away and long ago' following the application of his celebrated 'delayed-choice experiment' of 1984 which showed that the past is determined by our choice of what property to observe in the present $[18,19]$. In other words, it is only through the agency of (subjective) consciousness that the veiled and nonlocal becomes real and local. From this basis Wheeler went on to develop his well-known "it-from-bit" doctrine which proposed that all reality is information-theoretic in origin-a view which lead him to conclude that while information is fundamental to the physics of the universe, physical reality-as we know it-is created by the observer [20,21].

Notwithstanding the significance of these insights, this way of understanding the issue does not explain the nature of the "communication" that takes place at the point of interaction with "physical" reality - a better understanding of which, we propose, may lie in the idea of anticipatory systems.

\subsection{The Human Brain: A Pre-Conscious Anticipatory System}

In 1985 Robert Rosen defined an "Anticipatory System" as, 'a natural system that contains an internal predictive model of itself and of its environment, which allows it to change state at an instant in accord with the model's predictions pertaining to a later instant' [22]. Today the concept of anticipation is apparent in many fields including biology, engineering and artificial intelligence as well as cognitive and social science. Common to all is the proposition that an anticipatory system describes an ability to successfully foresee a future event or outcome in the present (i.e. prior to its happening) in any given scenario or context.

Crucially, from the point of view of "Living Systems" anticipation does not simply entail reacting to a present problem but rather comprises a response shaped in such a way as to foresee a potential future problem (i.e. with a view to averting it). It follows that whereas a reactive system can only react in the present to changes that have already occurred in the causal chain (i.e. in the past) an anticipatory system's present behavior involves aspects of the past, present and future. The presence of such a predictive model in a certain sense permits a future state to affect the present by serving to pull the future into the present (For further discussion see: $[23,24])$. It is this notion of "future causality" which sets the "Anticipatory Paradigm" against the "Reactive Paradigm" which has dominated the mechanical sciences for centuries.

It is also important to recognize that Rosen's usage does not simply refer to "good guess-work", "mathematical probability" or the ability to "see" or otherwise "sense" the immediate or distant future. Rather, Rosen suggests that there is information about self, about species and about the evolutionary environment encoded into the organization of all living systems (a view reminiscent of Kant). And this is the core of the matter, for in Rosen's usage the concept of information is not restricted simply to what we observe or learn or describe in the abstract; rather it refers to information that is embodied in the system itself. Hence, for Rosen, while not violating the concept of time established by (apparently) external "causal" events, organisms seem capable of constructing an internal surrogate of time as part of a natural model that can be manipulated to produce anticipation from which the idea of future causality derives.

It logically follows that this internal surrogate of time must run faster than real time [23]. Indeed, it seems obvious that most of our conscious activities (at least in terms of our everyday experience) are generated in a feed-forth as opposed to feed-back manner; which is to say, we typically make decisions now based on our understanding of the likely effects of our actions later. So natural is this to us that we normally don't even need to think about it. Accordingly, the essence of a feed-back system is that it is error-actuated which is in accordance with the problem-solving outlook engendered in the reactive paradigm (and typified by mechanistic-Cartesianism). By contrast, the essence of a feed-forth system is that the present change of state is determined by an anticipated future state. 
From this standpoint it can be argued that what makes the outcomes of mechanistic science seem consistent (and repeatable) more precisely represents the consistency of the way in which the physical systems have been arranged, observed and analyzed by "like-minded" (as in similarly trained/prepared) interpreters to, "provide model problems and solutions for a community of practitioners' (to use Kuhn's terms) [25]. Thus, by extension, it seems reasonable to surmise that the level of consistency of experimental outcomes in science is ultimately inextricably bound to the level of consistency achieved in the arrangement of the physical system/s and human consciousness combined.

Clearly, the implications of all this could be decisive from the point of view of human evolution, which appears fundamentally to be a communicative process. Crucially, however, what is less clear is the extent to which the human brain anticipates consciousness itself - something which must surely figure in any attempt to better understand consciousness and cognition and how the human brain functions as a natural anticipatory "communicative" system by which we evolve.

\subsection{The Communicative Phenomenological Process}

In 1964 Kornhuber and Deecke discovered that an electrical potential (of just a few microvolts - $\mu \mathrm{V}$ ) is visible in the brain before a subject becomes consciously aware of the action it relates to. They called it a "readiness potential" [26]. Building on this observation in the 1980's, Libet showed that unconscious activity took place some 350 milliseconds before a subject reported conscious awareness $[27,28]$. More recently, Haynes showed that brain activity is instigated as much as ten seconds before the subject is conscious of the decision - indicating that our brains are consciously aware before we are consciously aware [29]. The importance of Haynes' discovery cannot be overstated, for it leads us to further speculate that our brains are actually self-determining generators of reality - as Wheeler had previously proposed.

Related to this, in the field of cosmology the idea of "veiled nonlocality" describes the way in which consciousness disguises its nonlocal "wholeness" in order to produce local effects [30]. For Kak, veiled nonlocality is like a "fuzzification" that breaks up a whole system into several locally connected subsystems. This enables specific observations to be revealed in familiar classical terms of "localized" experience, giving the appearance of "cause and effect" and "solid reality" which we can more easily manage, while keeping quantum processes (Kant's "pre-mediated world") out of sight [30]-a view which is consistent with the experimental findings of quantum mechanics. From this basis it has been suggested that the brain is a processor of inputs as opposed to a mirror to reality and that consciousness is primary in the cosmos and not just an epiphenomenon of physical processes in a nervous system [30, 31]. From this we can further understand that consciousness and matter are not fundamentally distinct but rather are two complementary aspects of one holistic reality.

Such a view has been reinforced by the "Holonomic Brain Theory" developed by neuroscientist Karl Pribram (in collaboration with theoretical physicist, David Bohm) which proposes that the human brain is like a holographic storage network. Just as a hologram functions as a sort of lens which is able to convert an apparently meaningless blur of frequencies into a coherent image, the brain also comprises a "lens" of sorts which is able to convert the information it receives through the senses into the inner world of our perceptions; an "inner world" precisely because the brain itself resides in complete darkness. In short, Pribram believed that our brains construct reality by relying on information from the field [32].

Related to this, Marcer (1997) [33] has proposed a quantum mechanical model of evolution and consciousness based on the condition of "Phase-Conjugate-Adaptive-Resonance" (pcar). This upholds that when any three-dimensional object is illuminated by any kind of physical wave - "Holochory" (including quantum mechanical waves) real changes take place quite naturally in local amplitudes and phases of the incident illumination so as to encode/capture the image of the "object" (if that is the right term to use here). It proposes that not only would full wavefront reconstruction yield an immediate three-dimensional "Holochoric" perspective of the whole of the "object imagery" arriving at the sensory apparatus, it would also allow this new imagery in the form of a hologram to be compared with such previously stored imagery, and (crucially) allow it to be acted upon in accordance with the importance of that previous imagery as recognized from past experience. Thus 
cognition occurs when the information received by the percipient is brought into conjunction with the information already resident in the percipient's memory. In other words, the percipient (in the fullest sense) and the source of information are in a resonant relationship and thus inextricably engaged from the quantum level upwards.

Such a view is supported by growing evidence from a wide range of associated fields. For example, other experiments conducted by Libet in the 1970's demonstrated that we also "feel" with our brains [34] while others by the biophysicist Fritz Albert Popp identified bio-photons showing how all biological systems transmit light and information, their atoms interlinked in a continuous field of communication [Popp ed. et al., 1992] [35]. Clear parallels can also be drawn with the "Santiago Theory" of Maturana and Verela which states that, 'Living systems are cognitive systems, and living as a process is a process of cognition [which] ...is valid for all organisms, with or without a nervous system' [36]. Similarly, Sheldrake's theory of "Morphic Resonance" posits that, 'memory is inherent in nature' and may be responsible for "telepathy-type" interconnections between organisms' [37, 38] - something which might offer a way of explaining why species (including plants?) evolve in a remarkably consistent way across the world without ever having come into physical contact with each other. And, as we have already noted, every human brain is unique, which is why your reality differs from my reality.

When we consider all this in relation to the discoveries of Haynes et. al., we can reason that wave frequencies are initially received by the brain and fed into our sub-conscience. After this they are transformed and projected as (our) reality in a process of conscious mediation which may take up to ten seconds - with the implication that the brain functions as a receiver and a projector. The suggestion that the brain functions in this "twofold" way was recently reinforced by research undertaken by Keller [39] based on large-scale mapping of brain networks and their functional architecture, which concluded that, 'sensorimotor and posterior temporal regions are likely the major cortical projectors' (authors' emphasis). Thus projection seems to be an essential feature of what we here term a Communicative Phenomenological Process which lies behind, anticipates and informs evolutionary adaptation/s.

But surely there must be a reason as to why the brain functions in this way? Why, for example, project one reality rather than another? And could understanding this further deepen our understanding of human evolution?

\subsection{Conscious Selection: Signification, Meaning and Action in Living Systems}

Jacob von Uexküll once said, 'All the features of objects are in fact nothing else than the perceptive characters which are attributed to them by the subject with whom they have a relation' [40]. In order to contextualize this seemingly prophetic claim, Uexküll made use of the term "Umwelt" (from the German "environment") by which he meant, "the biological foundations that lie at the very epicenter of the study of both communication and signification in the human [and non-human] animal' [40, 41, 42].

Uexküll further theorized that organisms may have different individual "Umwelten" though they share the same general environment. From this basis he suggested that, 'only the phenomena which have a meaning for the animal subject are changed into nervous excitations' (authors' emphasis) [40]. In other words, that which has no meaning to us in a given context is not communicated and we remain unaware (and undirected).

In considering this it is interesting to further note that Barkow proposed that human cognition has a domain-specific structure, with the implication that cognitive domains are evolutionary and exist in the human brain as a result of Natural Selection [43]. More recently, Spelke has argued that such cognition may include features like reasoning about objects, other intentional agents, language, and number [44]. These views are also consistent with the theories of "Domain Specific Learning" which likewise suggest that human beings have many independent, specialized knowledge "structures" (as opposed to one cohesive knowledge structure) [45]—in some ways reminiscent of (perhaps replicated in) institutionalized Cartesianism.

All things considered, "Information Processing" surely appears to be a suitable way of understanding how challenges in the environment are overcome by psychological mechanisms. This may include, for 
example, our ability to reason and abstract to make sense of our environment and take the necessary action. But what is most important to note here in terms of human evolution is that transformations of information can be just as specialized as any other physical transformation and requires equally specialized psychological mechanisms to ensure successful adaptation. Hence, in time, through the processes of adaptation these psychological mechanisms would seem to reproduce inborn attentional biases towards particular classes of information-what we might call the evolutionary function of the "Communicative Phenomenological Process".

In line with this, Berthoz proposed that the human brain, 'transforms the perceived world according to rules of symmetry, stability and kinematic laws derived from principles of maximum smoothness.' These rules, 'allow the simplification of neurocomputation to speed up action... [by] ...selecting relevant information that registers with its repertoire of possible actions' [39]. And, according to Uexküll, it is the "action repertoire" of each species which, "specifies the selection of meaningful, significant information that is being searched for actively... [to] ...ensure the relevant action necessary to survival' [39].

We suggest that this process of "Conscious Selection" is inherent to the "Communicative Phenomenological Process" and ultimately comes to define the specific "Umwelt" necessary for each subject (and species) to successfully engage the wider world, and delineates the intrinsic anticipative capacity necessary to evolve in and create the best possible environment conducive to life. In other words, those things that we consider most meaningful and significant to our existence (individually and collectively) by way of "Conscious Selection" augments the "Communicative Phenomenological Process" which, in turn, provides the necessary directionality of evolution and any subsequent physical adaptations. Such a view has recently been further reinforced by research in the emerging field of epigenetics.

\subsection{Epigenetics and Conscious Selection: The Evolutionary Function of Values}

It was Gregor Mendel's "law" regarding the segregation of discreet hereditary units which introduced the concept of the "Gene" as the exclusive agent of heredity, giving rise to the pre-eminent Mendelian model of inheritance that exists to this day. However, it has become increasingly clear that this model is incomplete. In 1982 Lipton, for example, considered how quantum physics might be integrated into an understanding of the cell's information processing systems and discovered that the "brain" of a cell is not located in the nucleus as previously thought, but in its membrane or outer surface. His subsequent research suggested that the environment, operating through the membrane, controlled the behaviour and physiology of the cell - a discovery that contributed to the founding of epigenetics (non-generic inheritance)

According to Bonduriansky, by decoupling phenotypic change from the genotype, non-genetic inheritance can circumvent the limitations of genetic inheritance and influence population dynamics and alter the defining landscape, thereby influencing long-term evolution [46]. Thus, whereas genetic inheritance can be defined as any effect on offspring phenotype brought about by the direct transmission of DNA sequences from parents to offspring, we can define non-genetic inheritance as any effect on offspring phenotype brought about by the transmission of factors other than DNA sequences - either directly from parents or indirectly from more remote ancestors.

Non-genetic inheritance thus comprises processes whereby the environment within which an ancestor's genes reside, which is necessarily conditioned by the life-style patterns which have evolved as a result of that particular environment (and vice versa), influences development in descendents. This may include the way in which parental behavior can influence inherited learned behaviors which can exert a powerful influence on the development of the brain in offspring. Crucially, non-genetic inheritance can also involve the transmission to offspring of phenotypic or epigenetic states inherited from ancestors but not modified by environmental input during the individual's lifetime and may thus be unrelated to parental genotype. It has been suggested that, for this reason, "Cultural Variation" has become especially pronounced in humans. In "Dual Inheritance Theory" (DIT), for example, "Culture" is defined as information and behavior acquired through social learning (i.e. sociotypic factors) (authors' term) [47].

From this basis the epigenetic concept of "Transgenerational Phenotypic Plasticity" describes the way in which "plastic" responses in the parental generation enable them to alter development in offspring, 
even if the offspring themselves do not experience the inducing contextual (that is, sociotypic and envirotypic) factors. This, it is proposed, can enable populations to persist in the face of change that is too rapid for purely genetic adaptation (which lacks plasticity). Although initially such changes can be purely phenotypic, it is held that they can in the long-term ultimately affect the course and rate of evolution per se. [46, 48, 49]

We can readily recognize the effect of "Transgenerational Phenotypic Plasticity" in humans. For example, in most human populations lactase secretion ceases after weaning. However, in some European and African populations that continued the tradition of maintaining domesticated cattle, the use of milk in the adult diet spread through "Cultural" transmission (i.e. a sociotypic influence). This cultural development generated selection on genes that regulate lactase secretion, favoring an allele that causes continued lactase secretion after weaning. This evolutionary change, in turn, reinforced cultural selection favoring the use of milk by enabling more adults to digest milk effectively. In other words, non-genetic inheritance brought about a change in selection on genes, causing evolution which, in turn, reinforced non-genetic inheritance [46].

What we can learn from this is that epigenetics suggests that it is our perception of the environment which ultimately determines our DNA, not the other way around. The importance of this distinction cannot be overstated in that it implies that just as we create our reality - our unique "Umwelt" (as Wheeler, Uexküll etc. had previously proposed) we also create ourselves and it is (decisively) that which we consider most meaningful and significant which influences - through "Conscious Selection" - our subsequent choices and actions. From this we can further deduce that projection (as discussed above) is a condition of our heredity in as much as we anticipate and consciously select that which most favors our continued and (arguably) most fruitful existence. Hence, our reality is not merely shaped by input of raw information, but is profoundly shaped by our biology and the way that our minds are constituted (including our values, preferences, beliefs, ideals etc.) which, in turn, forms the basis of the communicative nature of our being, and arguably all beings.

It logically follows that shared values, preferences, beliefs, ideals etc. would be conducive to shared judgements and actions and a shared reality. This would seem to be further borne out by recent research in the fields of evolutionary psychology and evolutionary biology which revealed the molecular genetic basis of mathematical ability and associated this with autistic traits as well as schizophrenia and other learning difficulties [50], indicating a hereditary link between mind, body and other contextual factors; while according to Anand, only 5-10\% of all cancer cases can be attributed to known genetic defects, whereas the remaining $90-95 \%$ have their roots in the environment and lifestyle [51]; and a recent report by the Center for Disease Control and Prevention predicts that the regular use of Caesarean sections throughout the West in recent decades has lead to an evolutionary increase of fetopelvic disproportion rates by $10-20 \%$ [52]; and, finally, it is commonly known that a significant portion (up to one third) of all medical healing is the result of the so-called "Placebo Effect".

By conceiving of evolution in this way we can appreciate that the ways in which human beings organize and conduct themselves-individually and collectively in communities and societies and civilizations and cultures more broadly-may or may not be conducive to our successful evolution. In this connection, it was argued at the beginning of this paper that the pervasive influence of commonly held values, beliefs and ideologies etc. associated with Modern "Western" Civilization has - in the form of economic globalization - undermined the world's cultural diversity and set humanity on an unsustainable evolutionary trajectory which must now be addressed. It is with this in mind that in the remainder of this paper we propose an alternative view of human evolution in which human signification, meaning and action are broadly identified as central agents of constructive evolutionary change for a sustainable future.

\section{A NeW Vision ANd HyPothesis on HumAn Evolution}

\subsection{Characteristics of "Civie" and Human Evolution}

In this section we discuss our futuristic view of human evolution by arguing for the potentiality of "Civie" (a native Culture "creating-integrating-enriching" human factor) which (we propose) 
influences the direction of future human evolution in line with the arguments detailed above. Civie is characterized by a "self-reproducing, self-proliferating, self-organizing and self-enlightening" purposeful human factor, as well as by an "empathizing, collaborating, communicating and problemsolving" future-oriented human factor. In this way Civie is constantly stimulating and/or stimulated by the prevailing and changing human mental and physical activities relevant to Cultural enrichment far beyond "imitation" and "memory" attributed to Meme (i.e. by Dawkins). Such human activities refer to the enhancement of creativity, intelligence, awareness, cognition, sentience, insight, foresights, empathy, morality, social ethics, linguistic capacity, future orientation, complex perspectives, and so on.

According to Dawkins, it was the "Gene soup" in the long duration of time which came to create the human brain. In our opinion, however, Civie has come to provide the human brain and our related complex sensorial organs with increasingly complex and diverse Cultural and intellectually stimulations in order to constantly enhance overall human capacity. Such on-going complex and diverse stimulations provided by Civie are central to our hypothesis of Native Culture-enriching, anticipatory, open-ended human evolution which projects to the future.

In view of this we contend that Civie, Meme and Gene have worked collaboratively (not selfishly) for constant mutual reinforcements as well as for human survival, well-being and sustainable selfevolution [5]. In the process of creating and enriching diverse Native Cultures, Civie may have collectively interacted with Meme for mutual reinforcements conducive to a human future orientation and harmony-seeking features [5]. We further suggest that Civie and Meme may have interacted collaboratively with Gene for the expansion of human brain capacity in terms of memory, imitation and linguistic communication (among other things) where Civie, most likely, has influenced Meme which, in turn, influenced Gene, with different time-lags, respectively. In addition, Civie may also have constantly augmented the complex and Native Culture-enriching human capacities conducive to creativity, intelligence, awareness, cognition, sentience, empathy, wisdom, insight, morality, languages, future orientation, foresights, and so on, while Meme may have spread fast and far the constantly enhanced Civie through receptive human brains of growing capacity.

From this basis the authors propose that such long-term mutual/collaborative interactions between and among Civie, Meme and Gene may have resulted in the enrichment of diverse Native Cultures across the world, while human beings, within the nurturing context of their respective Native Cultures, have come to accept Culture-oriented greater social commitments, responsibilities and versatile activities for their continued survival, well-being and sustainable self-evolution.

We further suggest that Civie may have acquired a reasonable "amity-enmity" balance conducive to social harmony and necessary for peace-and-amenity oriented social organization; a reasonable "spiritual-material" balance conducive to personal integrity and necessary for human discretion and maturation (and which is crucial to maintain the moral and ethical dimension of society); a reasonable "altruistic-self-interested" balance conducive to relational mutuality and necessary for human collaborative consciousness and mutual/reciprocal sharing (for empathetic and symbiotic coexistence); a reasonable "collective-individual" balance conducive to social solidarity and necessary for reliable and friendly social relations (and which enables people to collectively endure the dangers inherent to society); and a reasonable "traditional-progressive" balance conducive to societal continuity and necessary for long-term accumulated human flexibility and versatility.

In accordance with such features, Civie may have provided culturally and socially important wisdom, long-term orientation to the future and complex human dispositions, deliberate-purposefulanticipatory foresights, together with stimulating the human inclination towards mutuality-andsolidarity - inducing collaboration, empathy, compassion, tolerance and moderation, and so on. Through all these special natural human attributes, Civie may have worked constantly for Cultureenriching and ethnicity-proliferating human capacities by expanding a "morality circle" or "empathy circle" to shape and inform ever larger human societies [53]. And it may also have worked constantly for natural-cultural strategies of symbiotic well-being and harmony between humans and other living beings. 


\section{2. "Civie" and Evolutionary Trilateral Interactions}

As a complex "self-reproducing, self-proliferating, self-organizing and self-enlightening" purposeful human factor as well as a complex "empathizing, collaborating, communicating and problemsolving" future-oriented human factor, Civie is depicted in a Venn diagram (shown in Fig. 1) with Meme and Gene to indicate continuous trilateral-interactions of mutual reinforcements. [5]

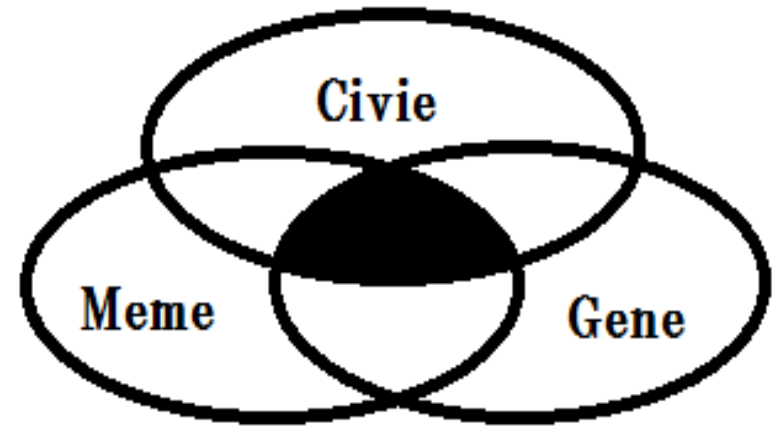

Fig1: A Trilateral Interactions of Civie, Meme and Gene

The overlapped area in Fig. 1 ("Area B" in black) shows Civie, Meme and Gene as indispensable factors trilaterally interacting for mutual reinforcements in human evolution on the realistic assumption that the respective factors change at much different speeds. Thus, Area B may imply a variety of shifting/changing combinations for the mutual reinforcements in the process of trilaterally interacting Civie, Meme and Gene. Also, Area B, representing "all things and all changes in humanity", may resemble a "black hole" with its mysterious mass energies that change constantly, accompanying little known forces of sucking, melting, fusing, condensing, light-blocking and other activities.

In this sense Area B is, more likely, a microcosm of the Universe with the known-and-unknown dynamics of mass energies and their little known effects on the change of the microcosm. The mysterious phenomena of dynamically changing interactions and mutual reinforcements among Civie, Meme and Gene within Area B are mostly unknown and hardly explained. The authors' propose that such little-known complex and mysterious phenomena may involve processes of adaptation and mutation through "Conscious Selection"-"Natural Selection" in human evolution.

It surely seems reasonable to suggest that the on-going trilateral interactions and mutual reinforcements among Civie, Meme and Gene may have helped to shape diverse human societies including Native Cultures, economies, beliefs, arts, technologies, and so on - broadly commensurate with the respective natural, climatic, geographical, geological and geopolitical environments. The way of Civie working as such, together with Meme and Gene, may further suggest normal collaborativeconscious human endeavors in each society as well as varying enrichment of diverse Native Cultures across the world.

The trilateral interactions and mutual reinforcements of Civie, Meme and Gene may also reflect a perpetual integration of human value aspect ("time-and-mental" dimensions) with human real aspect ("space-and-material" dimensions) for a trilateral virtuous circle/spiral of each society's holistic Culture enrichment, balanced socioeconomic development and comprehensive human-personal development $[54,55,56,57]$. Similarly, such trilateral reinforcements may also suggest an ideal of constant interactions between/among human beings, giving rise to important social values in the respective natural, climatic and other environments such as, social harmony, personal integrity, social solidarity, societal continuity and relational mutuality - all of which is discussed in detail in the following sections.

\section{INTEgRAl HARMONY AND THE REDIRECTION OF HUMAN EVOLUTION}

\subsection{Native Culture and Modern Civilization}

Generally speaking, "Native Culture" (viz., a harmony/peace-oriented and reasonably sound holistic society-specific culture) constantly interweaves its natural system, geopolitical system, belief system, 
social system and social value system, as innumerable generations of the people accumulate knowledge/wisdom (among other things) based on their experience, imagination, insight and foresights, constantly preparing for a viable future. Thus, it is necessary to emphasize that Native Culture is, by definition, enriched constantly through the process of human collaborations for integrating the things that go to make up culture. Hence, constant enrichment of Native Culture is considered most important when aiming at the future viability of a given society. It is, therefore, arguable that Native Culture largely works for the people and society by amicably accommodating, subsuming, integrating, modifying and sublimating personal-character differences, income-wealth disparities and social-and-personal contradictions (among others), for maintaining its overarching function for harmony and a viable future. For Native Culture has natural inclination tending towards the deepening and enriching itself for harmonious/peaceful/amicable lifestyles within the relevant society in view of a viable future.

The authors contend that such overarching social harmony and sustainability should be considered against the background of our ever-shrinking and/or ever-fragmented "mental-and-physical" world largely attributable to the modern mechanization of humanity and the "reckless run" of Modern Civilization, which are driving humanity and the life giving/sustaining environment towards destruction $[58,59]$.

More specifically, economic globalization, by means of the neo-liberal market fundamentalism (abbreviated as "Market") and the Market Value System , accompanied with the IT revolution in communication and transportation, has accelerated a worldwide movement towards the consolidation of wealth and power into the very small minority hands of already rich and strong. Also, economic globalization as means for the minority's centralizing the world has encouraged standardization, subjugation, unification and mechanization of humanity and human societies. Such a "Cartesian" conditioning of our "mental-and-physical" being may provide a figurative impression of the rapidly shrunken human dimension characterized by isolated atomistic and mechanistic beings.

Of more than seven billion people (many of whom are atomized and isolated in modern times) who live on our Insular Planet, too many are compelled to engage in "life-or-death" competition under the worsening scarcity of natural resources and the ill-advised human knowledge/capacity. This scenario is largely due to the highly manipulated, rapid growth of production, consumption, futility and waste by the plutocracy-driven modern power structure ("Big Market"), in addition to the similarly manipulated population explosion. More importantly, perhaps, it is due to the small minority's selfcentered and insatiable accumulation of wealth-and-power by manipulating the global economic system, for example, by creating and utilizing the networks of Central Banks and Offshore Centers/Tax Havens [57].

The forced and manipulated predatory competition resulting from this has rapidly and severely damaged and devastated diverse Native Cultures, social value systems, belief systems, personal morality, social ethics, and natural-and-social environments across the world. Worse still, the Marketinduced, greed-driven, transient and blind technological innovations under such predatory competition has rapidly widened the personal-national-global gaps which exist today between the rich and the poor by such means as incessantly shifting income, wealth and amenity from the latter to the former, marginalizing and mechanizing the latter in the process. Such an unsustainable global reality has made confrontational and predatory competition imminently dangerous to the viability of our future [61].

\subsection{Market Value System: the Complex Modern Drive}

In view of our discussion above, the emerged modern "core" value system can be summarized as the Market Value System that consists of five fundamental values, viz., Antagonism, Materialism, Individualism, Progressivism and Egotism, as shown in Fig. 2. This indicates that the Market Value System represents the "Core Synergism of Modern Civilization" or the "Complex Modern Drive" [62] This value system focuses on the strong attachment of Modern Civilization to power aggrandizement 
which is represented by its central value - Antagonism ("aggressive/predatory competition") - that interacts to ensure mutual reinforcements with Materialism, Individualism, Progressivism and Egotism (all which interact with one another for mutual reinforcements) [62]. It is this grossly lopsided value system which constantly drives the aggressive and predatory activities to lead to the destruction of diverse Cultures and social value systems, as well as to the absence of empathy, compassion and tolerance. Such value system has become the Complex Modern Drive, leading towards a state of eventual human and societal destruction across the world.

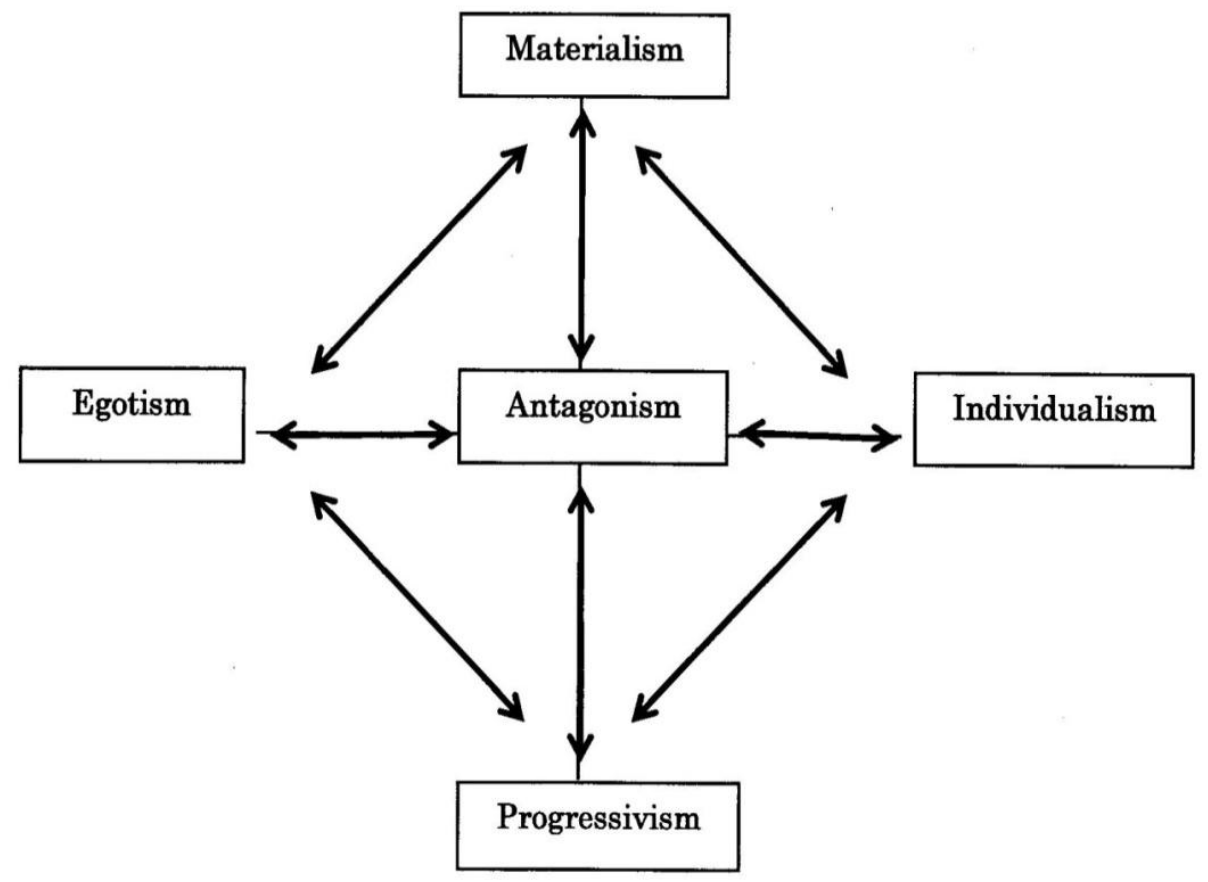

Fig2: Market Value System as the Complex Modern Drive

The Market Value System also reflect the deep-seated excesses and maladies of Modern Civilization, which produce "paranoid personality" for aggressive/predatory market competition, money-andmaterial-centered lifestyle, self-aggrandizing atomistic human entity, profit-driven innovation for economic expansion, and egocentric obsession with wealth and power. Such modern paranoid personality is clearly indicated by Fig. 3 (below) which shows how modern thoughts and ideologies have upheld only the "right-hand-side values" of the fundamental binary oppositions, respectively, of "Amity versus Enmity", "Spiritual versus Material", "Social versus Individual", "Traditional versus Progressive", and "Altruistic versus Self-interested". For visual clarity, the right-hand side ovals are "shaded". Such one-sided value system has encouraged Antagonism, Materialism, Individualism, Progressivism and Egotism, while at the same time negating the many human mutual benefits that arise from a sound social value system. 


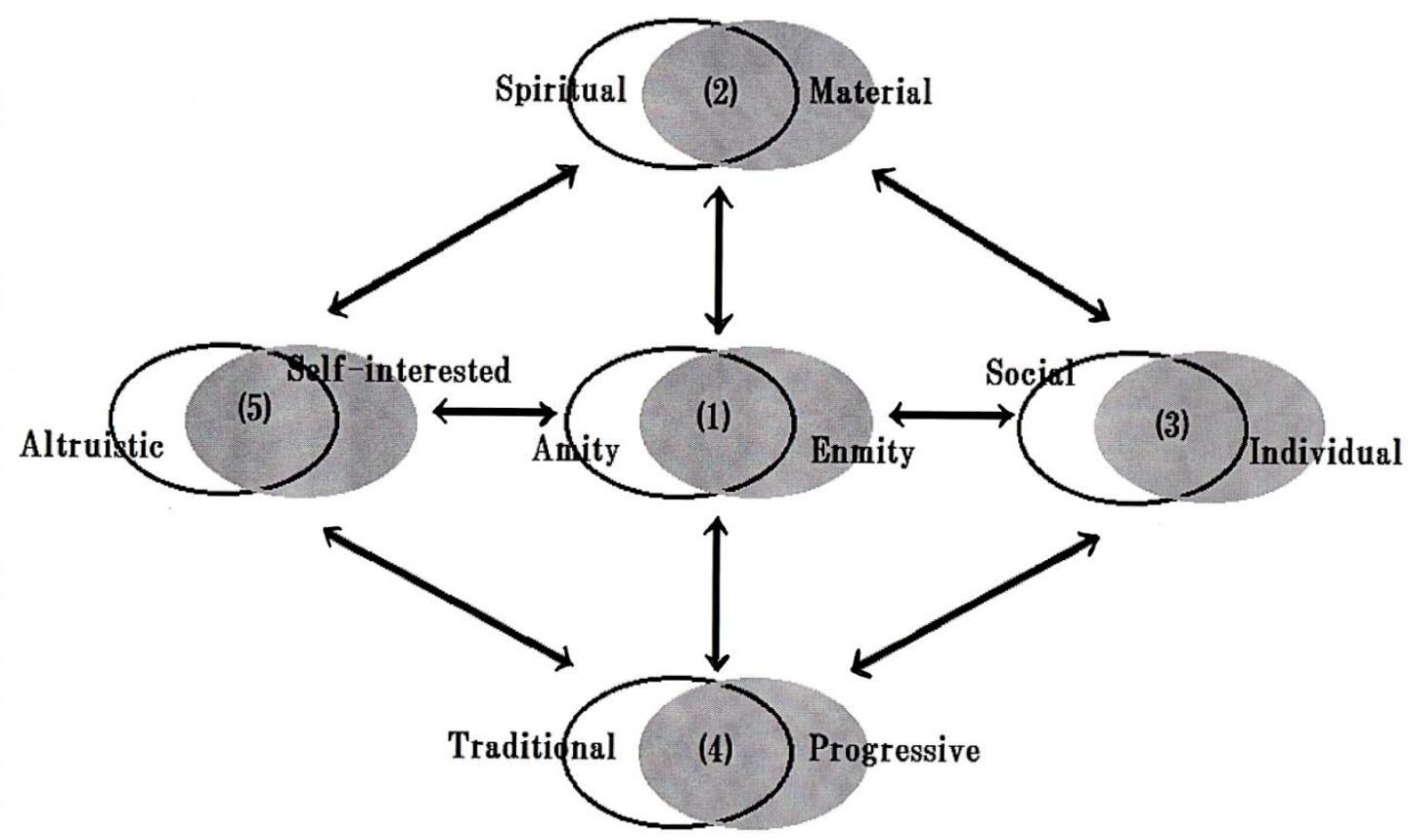

Fig3: Social Value Systems with Opposite-Value Spheres

In the above diagram, all the actions for integrations/sublimations of the respective "binary oppositions" take place constantly in the respective "overlapping areas" or "intersections" of the respective "opposite-value ovals". The respective "intersections" are numbered from (1) to (5), and the resulting sound fundamental values - sublimated values - are now named as: (1) social harmony (sublimated from "Amity-Enmity" integration), (2) personal integrity (sublimated from "SpiritualMaterial" integration), (3) social solidarity (sublimated from the "Social-Individual" integration), (4) societal continuity (sublimated from the "Traditional-Progressive" integration), and (5) relational mutuality (sublimated from the "Altruistic-Self-interested" integration). All of these mutuallyreinforcing sublimated values put together indicate Native Culture-based sound social value system [63].It cannot emphasize too much the importance of constant integration and sublimation for the upto-date mutual reinforcements among social harmony, personal integrity, social solidarity, societal continuity and relational mutuality in order to overcome the excesses and maladies brought on constantly by Modern Civilization. However difficult it may seem, it is indispensable for all of us to challenge the actual difficulty by moderating and modifying our excesses of aggressive/predatory competition, material-centered lifestyle, self-aggrandizing individualism, profit-seeking blind innovation, and self-seeking enclosure of common benefits.

\subsection{Normative Framework for Integral Harmony}

Therefore, we suggest that in order to have a future at all one last straw to hold on to may be one's own Native Culture with its respective social value system, though badly battered and dilapidated, to potentially open up ways for future survival, wellbeing, comfort and harmony. Hence in order to avoid our own human-personal self-destruction it may be essential for us to consciously seek worthwhile human collaborations with a view to reproducing sound social value systems for eventual restoration and enrichment of Native Cultures across the world. The authors uphold that such collaborations are indispensable in instituting a sound value system in each society as a means to reinforce human-personal maturation and personal integrity, rectify politico-economic ills, improve social health, encourage broad-minded tolerance, mutual respect and collaborative consciousness, and duly promote Sustainable Development for a viable human future [58].

In order to counterbalance and rectify the malaise of Modern Civilization, in particular, the Market Value System, a sound and dynamic social value system based on "imaged" sound Native Culture (or the normative framework for "Integral Harmony") need to be adopted by each society. Such social value system must include the values pertinent to social harmony (the fundamental and central value 
sublimated from the "amity-and-enmity" human inclinations), personal integrity (the fundamental value sublimated from the "spiritual-and-material" human inclinations), social solidarity (the fundamental value sublimated from the "social-and-individual" human inclinations), societal continuity (the fundamental value sublimated from the "traditional-and-progressive" human inclinations) and relational mutuality (the fundamental value sublimated from the "altruistic-and-selfinterested" human inclinations).

Through the constant and mutual interactions between and among the sublimated fundamental social values, the normative framework for Integral Harmony ("Integral Harmony", in short) must coordinate, integrate and harmonize over time all such social values for a lasting coherence of Culture-and-society. Integral Harmony provides not only for social overarching harmony but also for societal sustainability. In other words, Integral Harmony is assumed here to revitalize/reinforce itself constantly by integrating, harmonizing and sublimating the fundamental binary oppositions.

The following diagram (Fig. 4) simplified from Fig. 3 (above) now indicates the dynamic relations of fundamental social values, viz., Harmony, Integrity, Solidarity, Continuity and Mutuality. Fig. 4 also emphasizes Harmony (social harmony) as the central value of Native Culture, which interacts simultaneously and respectively with Integrity (personal integrity), Solidarity (social solidarity), Continuity (societal continuity) and Mutuality (relational mutuality). Accordingly, Harmony/Amenity shown as the pivotal social value directly interacts and mutually reinforces with all four "combinations" of fundamental social values, viz., Integrity/Humanity, Solidarity/Reliability, Continuity/Flexibility and Mutuality/Viability. These "combined" social values must directly and constantly interact and mutually reinforce with the three neighboring ones, respectively.

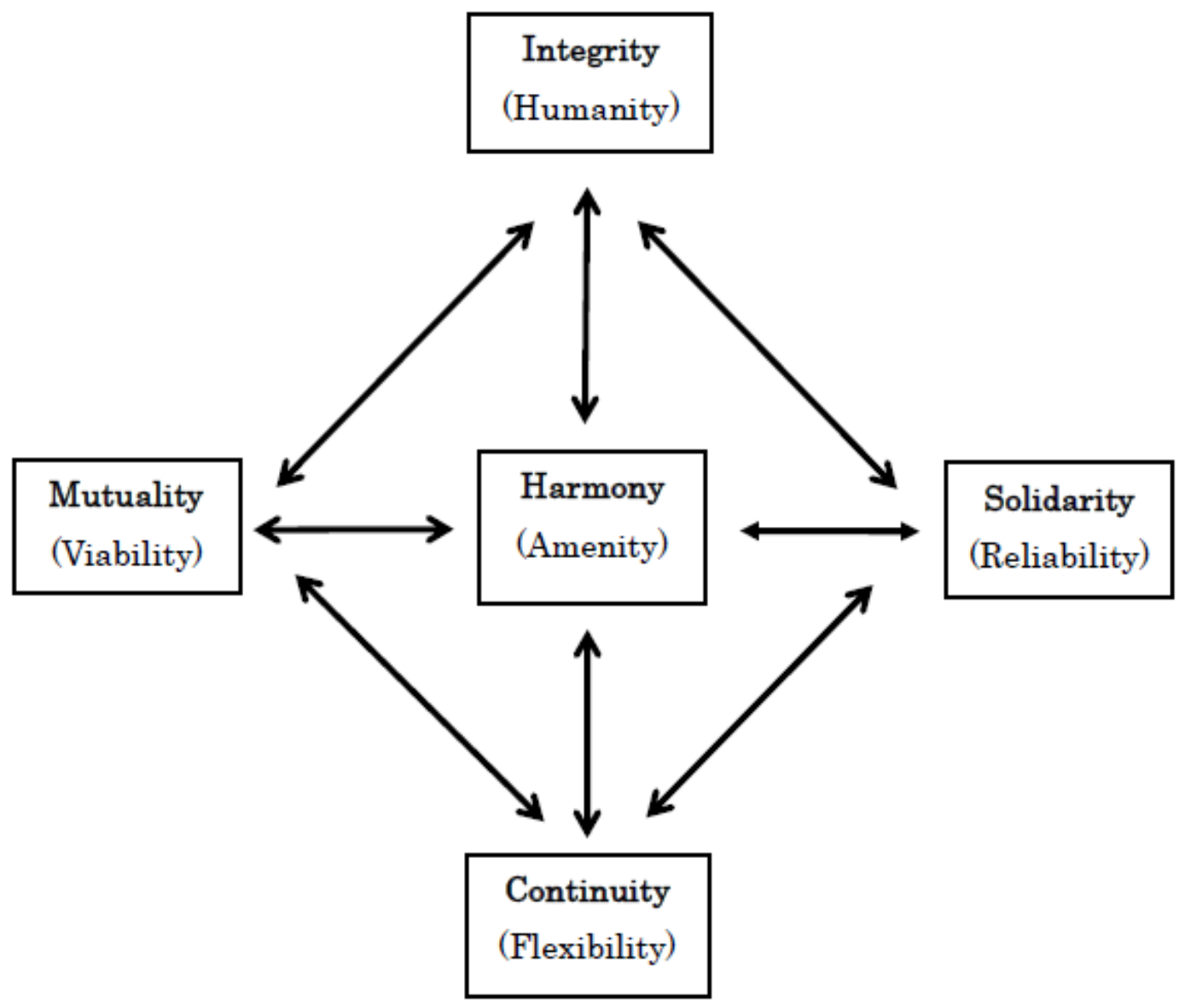

Fig4: Sound Social Value System

The pivotally important social value, social harmony (Harmony), reminds us of the badly displaced harmony in our contemporary human relationships. Also, social harmony urges us to moderate and rectify the inculcated-and-ingrained exclusionism and antagonism among competing religious beliefs and political ideologies, as well as among competing self-interested economic entities and even 
between husband and wife. It also reminds us of the existing deep divide between tradition and progress, between the elderly and the young and between the rich and the poor (among others), and urges us to revalue traditional wisdom and values incorporated into diverse Native Cultures.

Still further, social harmony suggests that an amicable, empathetic, ethical and amenity-oriented human society cannot be realized by forced unification, standardization, dogmatization and dehumanization of people by power, violence, money and the Market (market fundamentalism). Moreover, social harmony indicates the importance of constant and integral personal-spiritual processes of common and collaborative endeavors, in particular, for a viable human future.

Representing the spiritual-material human feature, personal integrity (Integrity) reminds us the importance of accelerating personal and spiritual enhancement, as well as of augmenting the working of Native Culture on human maturation, to counterbalance the prevailing excess of material/ mechanical-emphases. Also, social solidarity (Solidarity), representing the social-individual human feature, reminds us the importance of rectifying the prevailing excess of "individual emphasis" by augmenting common and collaborative endeavors, as well as by empowering the working of Native Culture on greater mutual trust and reliability.

Further, societal continuity (Continuity), representing the traditional-progressive human feature, reminds us the necessity of rectifying the prevailing excess of political and commercial emphases on "progress and economic growth" at the sacrifice of traditional values, natural environment and steady life-style, which has caused serious damage to the viability of our future. Moreover, relational mutuality (Mutuality), representing the altruistic-self-interested human feature, reminds us of the alarming human conditions largely lacking close personal relationships, empathy, compassion, tolerance and moderation, and urges us to work emphatically for common aspirations, mutual benefits, mutual well-being and mutual respects for a generally decent life to ensure our continued survival, sustenance and well-being.

In this way the dynamic Integral Harmony clearly reveals the importance of sound and dynamic Native Culture in attempting to address appropriate personal and spiritual development in each society in the interests of securing a viable future. Accordingly, we further anticipate that Integral Harmony by constantly integrating and sublimating "amity and enmity" will steadily moderate and modify Antagonism that, in reality, represents "predatory competition", "aggressive takeover", "exploitation of the weak", and "mental-material impoverishment of the majority". By constantly integrating and sublimating "the spiritual and the material", we also anticipate that Integral Harmony will steadily moderate and modify Materialism that, in reality, represents "mammon-ism", "plutocratic control over politico-economic activities", and the "mechanical view of humans, societies and the universe".

What is more, by constantly integrating and sublimating "the social and the individual", we further anticipate that Integral Harmony will steadily moderate and modify Individualism that, in reality, represents "individual self-aggrandizement" and "individual motivation to control the other" as well as legitimizing the winner's self-justifying "Might makes right" slogan. In addition, by constantly integrating and sublimating "the traditional and the progressive", we anticipate that Integral Harmony will steadily moderate and modify Progressivism that, in reality, represents "profit-motivated innovation for transient convenience", "manipulated growth-maniac economy", and "deceptive efficiency by inhuman exploitation of the poor-and-weak".

And, finally, by constantly integrating and sublimating "self-interest and altruistic-interest", we anticipate that Integral Harmony will steadily moderate and modify Egotism that, in reality, represents "self-seeking profit maximization", "unequal and unjustifiable market competition at the sacrifice of the weak", "own national interest over and above that of the remaining world" and "disrespectfulness to own people, other people and all Native Cultures".

The above discussion, although far from exhaustive, may provide us with a strong argument for a raison d'etre of sound social value system in each society, which reflects such aspects as our historical necessities, socio-political worldviews and human aspirations for well-being and viable future based on respectively different combinations of cultural, spiritual, social, natural, historical, economic, geopolitical, environmental and other factors. The absence of a reasonably sound social value system often tends to reflect human failings and sufferings deriving from ignorance, weakness, excesses and wrong-doings. Such failings and sufferings may include such things as land-water strife, 
warfare, tyranny, misrule, self-righteousness, self-aggrandizement, excessive exploitation, power hungriness and supremacy, greediness, selfishness and disrespect for life more generally. This is often further complicated and compounded by natural disasters such as, earthquakes, floods, tsunamis, volcanic eruptions, typhoons/hurricanes, tornados, famines, epidemics/pandemics, and so on.

Accordingly, almost all human failings and sufferings, as well as human aspirations for well-being and viable future, have no doubt been collectively and deeply memorized in, and integrated into diverse and respective Native Cultures and social value systems across the world in the form of collective knowledge/wisdom. In this way Native Culture has served to cushion, moderate or forewarn such human failings and sufferings.

Put more broadly and philosophically, diverse Native Cultures and social value systems have constantly absorbed and handed down the traces and lessons of various social-and-personal experiences and knowledge, as well as varying natural, climatic and environmental catastrophes. Thus, human beings, comprising complex spiritual, intellectual, biological, chemical and physical elements, have been constantly influenced, in one way or another, by their respective Native Cultures, social value systems, prevalent thoughts/ideologies, and the attitudes/behaviors of the preceding and the current peoples and their natural, physical, chemical and biological environments. Crucially, however, the contemporary value system which has been imposed by Modern Civilization and further augmented through economic globalization has no real Native-Cultural foundations.

With this in mind, and in view of the ensuing human moral/ethical/spiritual predicament, Integral Harmony, should provide a highly comprehensive, complex and compact arrangement to be applicable to each and all human societies. With Native Culture-based, multi-facetted, multilayered, integrated value structure that consists of highly generalized human moral/ethical/spiritual aspirations, the authors anticipate the following: our constantly and soundly adjusting Integral Harmony will function as a guideline for rectifying the prevailing human excesses and wrong-doings and as an enduring reminder of the human aspiration for a sustainable future.

As a sound Native Culture works dynamically, we also anticipate that Integral Harmony will help to maintain perpetual adjustments and mutual reinforcements between and among all the fundamental value components in accordance with the on-going natural-and-human environmental changes. Being nurtured and enhanced constantly by our respective Native Cultures, we further anticipate that dynamic Integral Harmony in each society will moderate and rectify the prevailing lopsided Market Value System consisting of Antagonism, Materialism, Individualism, Progressivism and Egotism, which has constantly mass-produced self-aggrandizing individuals, human excesses, failings and wrongdoings and, hence, the amplified incalculable human sufferings.

For more general long-lasting benefits worldwide, Integral Harmony may offer an appropriate guideline for the promotion of Sustainable Development in view of a viable human future. The consequential general human-personal maturation of the moral-ethical-empathetic aspects of humanity may steadily encourage common and collaborative endeavors. Accordingly, humans at large may also be guided to resist the self-seeking manipulation by the faceless, self-complacent and selfsufficient Big Market that has heavily inculcated and instigated people worldwide toward distorting/debasing their ethos and characters with the excessively lopsided ideologies and the Market Value System to go against Sustainable Development.

In order to help promote Sustainable Development for a viable human future, therefore, it is necessary to pursue earnestly and collaboratively sound and integral social value systems across the world, corresponding to Integral Harmony for the purpose of invigorating and accelerating a worldwide collaboration of resuscitating and enriching diverse Native Cultures.

It is clear from the arguments presented above that Sustainable Development requires an effective, comprehensive, integrated framework such as Integral Harmony that represents the integrated social fundamentals for properly regarding/valuing the "nature-human" integrality, communal living, collaborative consciousness, sound-life orientation and symbiotic lifestyle. Such framework for sound social value system, when accompanied with a proper long-term theory of well-balanced socioeconomic development [63], may reinforce its worldwide effect for collaborative-conscious promotion of Sustainable Development. 
It is equally clear that we humans have come to a major turning point by which we must choose and cultivate our mentality, attitude and behavior figuratively entailing "life over death" as well as "light over shadow". Thus, we contend that the prevailing "explosion paradigm" should be replaced as soon as possible in preference of a "sustainability paradigm" (or "balance paradigm") to herald the advent of a new Age of Sustainability [64].

Accordingly, we anticipate that the Age of Sustainability will be characterized by our futuristic view of human evolution-the steady processes of human-personal maturation, mutual respect and conscious collaboration with a view to building a decent global community [64] that embodies a common awareness of necessary long-term relational mutuality on our Insular Planet.

\section{CONCLUding NoTES}

Darwin's understanding of evolution was conceived and propagated within the context of a Cartesian paradigm which came to dominate the scientific and political institutions of the West in the modern era. This engendered a fractured worldview manifested in highly specialized forms of "mechanical" knowledge which tended to segregate "evolution" into the Biological, Physical and Spiritual dimensions, indicating a lack of unity and persuasion. This paper has sought to address this by pointing to a more comprehensive understanding of evolution of the kind only just beginning to reemerge now: i.e., a conception which accommodates complexity and is essentially unifying in its interpretation of the relationship between humankind and the world we inhabit, in terms of our biology, our physical being and our spirituality.

We have described this in terms of a Communicative Phenomenological Process by way of which the concept of information emerges as the foundation upon which all knowledge, all perception, and all life is actuated. From this basis we have argued that it is the ways in which we have come to value information, both consciously as individuals and biologically as a species, which determines that which we consider most meaningful and significant to our existence and (hence) most worthwhile pursuing.

We have utilized the term "Conscious Selection" to describe the many complex processes neurological, cognitive, contextual as well as values, beliefs, ideals etc. - which appear to be at play prior to Natural Selection (in the purely biological sense) and which provide directionality to our evolution. By conceiving of evolution in this way enables us to appreciate that the ways in which we organize and conduct ourselves - individually and collectively, in communities and societies and civilizations and cultures more broadly - is a determining factor of our evolution.

This understanding has drawn us to the critical role of diverse sound "Native Cultures" and, as we propose, their surrogates - "Integral Harmony" (the normative framework of social value system based on "imaged" sound Native Culture in each society) - in the absence or devastation of sound Native Cultures, for providing the right kind of directionality. With this in mind, we have sought to develop a more comprehensive and collaborative view of human evolution by combining Dawkins' concept of "Meme" with the biological "Gene" and our own term "Civie" - introduced to denote the complex human-cultural factor. Together, this forms the trilateral framework of human evolution which is now to be assisted consciously by Integral Harmony in each society to adjust constantly the human evolution into a sustainable human future. By collaborative-consciously and earnestly pursuing Integral Harmony worldwide, we believe humankind can enhance the necessary human qualities to counter the harmful effects of Modern Civilization and ultimately ensure our successful and sustainable evolution.

\section{REFERENCES}

[1] Kida, Hajime, et al., edited (1997); Shinka-ron (Evolution Theory) written by Ryuichi Yasugi; Konsaisu Nijisseiki Shiso-Jiten, Dainihan (Concise $20^{\text {th }}$ Century Dictionary on Thoughts, $2^{\text {nd }}$ Edition), Sanseido Co., Ltd., Tokyo, pp. 504-505.

[2] Dawkins, Richard (1976); The Selfish Gene; Oxford University Press (Japanese version, Rikotekina Idenshi by T. Hidaka, et. al; Kinokuniya Shoten, pp. 301-321).

[3] Graham, William (2015); Some Notes Toward a Theory of Persons; $12^{\text {th }}$ Symposium on Personal and Spiritual Development in the World of Cultural Diversity, $27^{\text {th }}$ International Conference on Systems Research, Informatics and Cybernetics, held in Baden-Baden, Germany, August 3-8, 2015. 
[4] Graham, William (2016); The Role of the Heart in the Evolution of Spirit, in: Personal and Spiritual Development in the World of Cultural Diversity-Volume XIII; edited by George E. Lasker and Kensei Hiwaki; IIAS, pp. 59-64.

[5] Hiwaki, Kensei (2016): A Futuristic View of Human Evolution, in: Personal and Spiritual Development in the World of Cultural Diversity - Volume XIII, edited by George E. Lasker and Kensei Hiwaki; IIAS, pp. 1-5.

[6] Darwin, C. (1871 $1^{\text {st }}$ ed.); The Descent of Man, and Selection in Relation to Sex; London: John Murray; Project Gutenberg E-text.

[7] Darwin, C. (1859); On the Origin of Species; London: John Murray

[8] Kant, I. (1781: $2^{\text {nd }}$ ed. trans. by F. Muller, 1922). Critique of Pure Reason. London: Macmillan; (Available at: http://files.libertyfund.org/files/1442/0330_Bk.pdf.

[9] Palimquist, S. (2010); The Kantian Grounding of Einstein's World View: (I) The Early Influence of Kant's System of Perspectives; Polish Journal of Philosophy 4.1, 45-64.

[10] Eisberg, R. \& Resnick, R. (1985). Chapter 3 - de Broglie's Postulate-Wavelike Properties of Particles; Quantum Physics: of Atoms, Molecules, Solids, Nuclei, and Particles (2nd ed.); London: John Wiley \& Sons.

[11] Davisson, C. J. \& Germer, L. H. (1928); Reflection of Electrons by a Crystal of Nickel; Proceedings of the National Academy of Sciences of the United States of America 14 (4); 317-22.

[12] Heisenberg, W. (1927). Über den anschulichen Inhalt der quantentheoretischen Kinematik und Mechanik (On the Perceptual Content of Quantum Theoretical Kinematics and Mechanics); NASA Reports Technical Server (NRTS); (English translation. Available at: https://ntrs.nasa.gov/archive/nasa/ casi.ntrs.nasa.gov/19840008978.pdf)

[13] Einstein. A, Podolsky B, \& Rosen N. (1935); Can Quantum-Mechanical Description of Physical Reality Be Considered Complete?; Phys. Rev. 47 (10); 777-780.

[14] Hassard, F. (2016). Cognition, Anticipation and Quantum Mechanic's Measurement Problem, in: Modeling and Simulation of Physical and Biological Systems Depending on Space, Time, Retardation, Anticipation, Vol. 1, edited by G. Lasker \& D. Dubois. IIAS; pp. 53-8.

[15] von Newman, J. (1996, $1^{\text {st }}$ pub. 1932). The Mathematical Foundations of Quantum Mechanics; Princeton Univ. Press; New Ed.

[16] Wigner, E. (1967, $1^{\text {st }}$ pub. 1961); Remarks on the mind-body question; Symmetries and Reflections, Indiana Univ. Press: Bloomington; 171-84; (Available at: http://www.projects.science.uu.nl/ igg/jos/foundQM/wigner.pdf)

[17] Schreiber, Z. (1995); The Nine Lives of Schrodinger's Cat; Quantum Physics (version 5 paper), Cornell Uni. Lib.; (Available at: arXiv:quant-ph/9501014v5)

[18] Wheeler, J. (2003, $1^{\text {st }}$ pub. 1978); The Past' and the 'Delayed Choice' Double-Slit experiment; The Tests of Time: Readings in the Development of Physical edited by L. Dolling: 486.

[19] Wheeler, J. (2006); The anthropic universe; Radio interview with Martin Redfern, Science Show, $18^{\text {th }}$ February 2006; (Available at: http://www.abc.net.au/radionational/programs/scienceshow/the-anthropicuniverse/3302686)

[20] Wheeler, J. (1990); Information, physics, quantum: The search for links; Zurek, Wojciech Hubert. Complexity, Entropy, and the Physics of Information.

[21] Stoica, C. (2013); The Tao of It and Bit; It from Bit or Bit from It? Springer Intl. Pub., 2015: 51-64.

[22] Rosen, R. (1985); Anticipatory Systems: Philosophical, Mathematical \& Methodological Foundations; Pergamon Press, Oxford.

[23] Louie, A. (2010); Robert Rosen's anticipatory systems; Foresight, Vol. 12, No. 3, Emerald: 18-29.

[24] Poli, R. (2010); The many aspects of anticipation; Foresight, Vol. 12, No. 3, Emerald: 7-17.

[25] Kuhn, T. (1996); The Structure of Scientific Revolution, $3^{\text {rd }}$ ed., Un9versity of Chicago Press.

[26] Kornhuber, H. \& Deecke, L. (1965); Hirnpotentialänderungen bei Willkürbewegungen und passiven Bewegungen des Menschen: Bereitschaftspotential und reafferente Potentiale (Changes in brain potentials with willful and passive movements in humans: the readiness potential and reafferent potentials); Pflügers Arch European Journal of Physiology 284: 1-17; (English overview available at: http://www.garfield. library.upenn.edu/classics1990/A1990CH18100001.pdf)

[27] Libet, B., Gleason, C. Wright, E. \& Pearl, D. (1983); Time of Conscious Intention to Act in Relation to Onset of Cerebral Activity (Readiness-Potential) - The Unconscious Initiation of a Freely Voluntary Act; Brain 106: 623-42.

[28] Libet, B. (1985); Unconscious Cerebral Initiative and the Role of Conscious Will in Voluntary Action; The Behavioral and Brain Sciences 8: 529-66.

[29] Haynes, J., Soon, S., Brass, M., \& Heinze, H. (2008); Nature Neurosci. 
[30] Kak, S., Chopra, D. \& Kafatos, M. (2014); Perceived Reality, Quantum Mechanics, and Consciousness; Cosmology, Vol. 18. Cosmology.com: 231-245.

[31] Kafatos, M., Tanzi, R., \& Chopra, D. (2011); How Consciousness Becomes the Physical Universe; Journal of Cosmology, Vol. 14. Cosmology.com

[32] Pribram, K. (1991); Brain and Perception: Holonomy and Structure in Figural Processing, Lawrence Erlbaum Associates.

[33] narcer, P. (1997); Consciousness as an Informational Phenomenon; Scientific amd Medical Network.

[34] Libet, B. (2004); Mind time: The temporal factor in consciousness; Perspectives in Cognitive Neuroscience. Harvard University Press.

[35] Popp, F. dt al., eds. (1992); Recont Advances in Biophoton Research and its Application; World Scientific, available at http://www.worldscientific.com/doi/pdf/10.1142/9789814439671-fmatter

[36] Maturana, H. \& Varela, Francisco J. (1980); Autopoiesis and Cognition: The Realization of the Living; Dordrecht: Reidel: 13.

[37] Sheldrake, R. (2008); Autobiography of Rupert Sheldrake; (Online resource available at: http://www. sheldrake.org/about-rupert-sheldrake/autobiography)

[38] Sheldrake, R. ( $2^{\text {nd }}$ ed., 2011); The presence of the past: Morphic resonance and the habits of nature; Icon Books.

[39] Keller, C., Honey, C., Entz, L., Bickel, S., Groppe, D., Toth, E., Ulbert, I., Lado, F., \& Mehta, A. (2014); Corticocortical Evoked Potentials Reveal Projectors and Integrators in Human Brain Networks; The Journal of Neuroscience, Jul 2; 34(27): 9152-63; (Available at: http://www.ncbi.nlm.nih.gov/pmc/ articles/PMC4078089/)

[40] Berthoz, A. (2009); The Human Brain "Projects" upon the World, Simplifying Principles and Rules for Perception; Neurobiology of 'Umwelt', Part of the series Research and Perspectives in Neurosciences: 17-27.

[41] Kull, K. (2010); Umwelt; Cobley, Paul; The Routledge Companion to Semiotics. London: Routledge: 348-9.

[42] Chien J-P. (2007); Umwelt, milieu(x), and environment: A survey of cross-cultural concept mutations; Semiotica, 167-1/4: 65-89.

[43] Barkow, J., Cosmides, L., \& Tooby, J. (1992); The Adapted Mind: Evolutionary Psychology and the Generation of Culture, Oxford: Oxford University Press.

[44] Spelke, E., \& Kinzler, K. (2007); Core knowledge; Developmental Science, 10.1: 89-96.

[45] Siegler, R. (2006); How Children Develop, Exploring Child Develop Student Media Tool Kit \& Scientific American Reader to Accompany How Children Develop; New York: Worth Publishers.

[46] Bonduriansky, R. \& Day, T. (2009); Nongenetic Inheritance and its Evolutionary Implications; The Annual Review of Ecology, Evolution and Systematics, 40: 103-25.

[47] Hassard, F. (2015); Towards Global Community: a Post-Autistic Transformation, in: Health Care and Intelligent Medicine Vol. 35, edited by G.. Lasker; IIAS.

[48] Dias, B., \& Ressler, K., (2014); Parental olfactory experience influences behavior and neural structure in subsequent generations; The Howard Hughes Medical Institute, Nat Neurosci., 17(1): 89-96.

[49] Mameli, M. (2004); Nongenetic Selection and Nongenetic Inheritance; The British Journal of the Philosophy of Science 55 (1): 35-71.

[50] Baron-Cohen, S., Murphy, L., Chakrabarti, B., Craig, I., Mallya, U., Lakatsova, S., Rehnstrom, K., Peltonen, L., Wheelwright, S., Allison, C., Fisher, S., \& Warrier, V. (2014); A Genome Wide Association Study of Mathematical Ability Reveals an Association at Chromosome 3q29, a Locus Associated with Autism and Learning Difficulties: A Preliminary Study; PLoS ONE 9(5): e96374. doi:10.1371/journal. pone.0096374 edited by M. Xoing, Univ. of Texas Schl. of Public Health, USA.

[51] nand, P., Kunnumakara, A. B., Sundaram, C., Harikumar, K. B., Tharakan, S. T., Lai, O. S., Aggarwal, B. B. (2008). Cancer is a Preventable Disease that Requires Major Lifestyle Changes; Pharmaceutical Research, 25(9): 2097-2116; (Available at: http://doi.org/10.1007/s11095-008-9661-9)

[52] Mitteroecker, P., Huttegger, S., Fischer, B. \& Pavlicev, M. (2016); Cliff-edge model of obstetric selection in humans; CrossRef Cited-by Linking Search Results PNAS 2016: 1612410113v1-201612410.

[53] NHK Special Crew (2012); Human; Kadokawa-shoten, Tokyo, pp. 216-217.

[54] Hiwaki, Kensei (2011); Culture and Economics in the Global Community: A Framework for Socioeconomic Development; Gower Publishing Limited, Surrey, U.K., pp. 145-146, 239-243, 264-267.

[55] Hiwaki, Kensei (2014a); Own Culture-based Integral Education for a Viable Human Future; Human Systems Management, Vol. 33, pp. 121-138.

[56] Hiwaki, Kensei (2014b); Life-long Integral Education: A Practical Approach, in: Life-long Integral Education for a Viable Human Future-Advances in Education: Volume XI, edited by George Lasker, Kensei Hiwaki and Ayten Aydin; IIAS, pp. 1-5. 
[57] Hiwaki, Kensei (2015a); Alternative Economics and Sustainable Future: Diverse Cultures/Beliefs/Values as Indispensable Factors; Cybernetics and Systems: An International Journal, pp. 588-604.

[58] Hiwaki, Kensei (2007); Economic Globalization as against Sustainable Development, in: Sustainable Development and Global Community - Volume VIII, edited by George E. Lasker and Kensei Hiwaki; IIAS, pp. 1-5.

[59] Hiwaki, Kensei (2013); Rationalist Trap: Personal and Spiritual Desolation, in: Personal and Spiritual Development in the World of Cultural Diversity-Volume X, edited by George E. Lasker and Kensei Hiwaki, IIAS, pp. 1-5.

[60] Shiga, Sakura (2013); Takkusu Heibun: Nigeyuku Zeikin (Tax Haven: Fleeing Tax); Iwanami Shinsho; pp. $12,24$.

[61] Hiwaki, Kensei (2014d); Survival Instinct, Culture and Sustainable Development, in: Sustainable Development and Global Community-Volume XV, edited by George E. Lasker and Kensei Hiwaki, IIAS, pp. 1-5.

[62] Hiwaki, Kensei(2017a): The Core Synergism of Modern Civilization, in: Advances in Synergetics Volume III, edited by George E. Lasker: IIAS: pp. 33-37'.Hiwaki, Kensei (2016c): Sustainable Development vis-à-vis Our Self-Interested Abuses, in: Sustainable Development and Global Community —Volume XVII, edited by George E. Lasker and Kensei Hiwaki; IIAS; pp. 1-5.

[63] Hiwaki, Kensei (2017b): Integral Harmony: Integrating/Reinforcing Framework of Social Value System, in: Personal and Spiritual Development in the World of Cultural Diversity-Volume XIV, edited by George E. Lasker and Kensei Hiwaki: IIAS: pp. 1-5".

[64] Hiwaki, Kensei (2017c): A Balance Paradigm for Post-Plutocracy: Toward Sustainable Development with Integral Harmony, Systems [MDPI] (22 February 2017), pp. 1-45. Free Access Online: http://www.mdpi. com/2079-8954/5/1/16/pdf.

\section{AUTHORS' BIOGRAPHY}

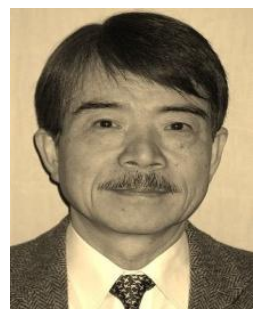

Kensei Hiwaki is Emeritus Professor at Tokyo International University, Japan, Heis also Distinguished Professor at the International Institute for Advanced Studies in Systems Research and Cybernetics (IIAS, Canada). Studying in USA since 1966, he earned BA (1970: Drew University, N.J.), MA (1972: Duke University, N.C.) and Ph.D. in Economics (1980: The City University of New York). An award-winning book (2011), Culture and Economics in the Global Community: A Framework for Socioeconomic Development, Gower Publishing, England, is one of his representative work.

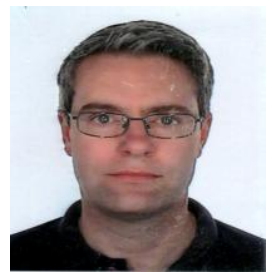

Frank Hassard is Professor of the International Institute for Advanced Studies in Systems Research and Cybernetics (IIAS). He achieved a Ph.D. on the theory of cultural heritage preservation in 2006 at Brunel University, UK, and has been a regular participant at the International Conference on Systems Research, Informatics and Cybernetics held annually in Baden-Baden, Germany, and published numerous peer-reviewed papers on a range of subjects.

Citation: Kensei Hiwaki, Frank Hassard. "Pursuing Integral Harmony in Sustainable Human Evolution". International Journal of Humanities Social Sciences and Education (IJHSSE), vol. 6, no.7, 2019, pp. 34-54. doi: http://dx.doi.org/ 10.20431/2349-0381.0607005.

Copyright: (C) 2019 Authors. This is an open-access article distributed under the terms of the Creative Commons Attribution License, which permits unrestricted use, distribution, and reproduction in any medium, provided the original author and source are credited. 